\title{
Concentrations of polychlorinated dibenzo-p-dioxins (PCDDs), polychlorinated dibenzofurans (PCDFs) and polychlorinated biphenyls (PCBs) in human milk from Ireland: temporal trends and implications for nursing infant exposure
}

\author{
Margarete Houlihan ${ }^{1}$, Nina Wemken ${ }^{2}$, Myra Keogh$^{1}$, Colman O’Riordain ${ }^{1}$, Conor Noone ${ }^{1}$, Julie Tierney ${ }^{1}$, \\ Claire Cellarius ${ }^{3}$, Kathy Cleere ${ }^{4}$, John J. Morrison ${ }^{3}$, Sean Daly ${ }^{4}$, Stuart Harrad ${ }^{5}$, Christina Tlustos ${ }^{6}$, Marie \\ Ann Coggins ${ }^{2}$

\begin{abstract}
'State Laboratory, Backweston Complex, Youngs Cross, Celbridge, County Kildare W23 VW2C, Ireland.
${ }^{2}$ School of Physics and the Ryan Institute, National University of Ireland, Galway H91TK33, Ireland.

${ }^{3}$ Department of Obstetrics \& Gynaecology, National University of Ireland, Galway H91TK33, Ireland.

${ }^{4}$ Obstetrics \& Gynaecology, Coombe Women's \& Infants University Hospital, Dublin D08 XW7X, Ireland.

${ }^{5}$ School of Geography, Earth \& Environmental Sciences, University of Birmingham, Birmingham B15 2TT, UK.

${ }^{6}$ Chemical Safety, Food Safety Authority of Ireland, Dublin D01 P2V6, Ireland.
\end{abstract}

Correspondence to: Prof. Christina Tlustos, PhD, Chief Specialist, Chemical Safety, Food Safety Authority of Ireland, The Exchange, George's Dock, IFSC, Dublin D01 P2V6, Ireland. E-mail: CTlustos@fsai.ie

\begin{abstract}
How to cite this article: Houlihan M, Wemken N, Keogh M, O'Riordain C, Noone C, Tierney J, Cellarius C, Cleere K, Morrison JJ, Daly S, Harrad S, Tlustos C, Coggins MA. Concentrations of polychlorinated dibenzo-p-dioxins (PCDDs), polychlorinated dibenzofurans (PCDFs) and polychlorinated biphenyls (PCBs) in human milk from Ireland: temporal trends and implications for nursing infant exposure. J Environ Expo Assess 2021;1:2. https://dx.doi.org/10.20517/jeea.2021.02
\end{abstract}

Received: 7 Sep 2021 First Decision: 30 Sep 2021 Revised: 28 Oct 2021 Accepted: 9 Nov 2021 Published: 19 Nov 2021

Academic Editor: Boris Johnson-Restrepo Copy Editor: Yue-Yue Zhang Production Editor: Yue-Yue Zhang

\begin{abstract}
Aim: The elucidation of temporal trends in human exposure to polychlorinated biphenyls (PCBs) and 17 polychlorinated dibenzo-p-dioxins and furans (PCDD/Fs) since the previous Irish human milk surveys and to evaluate the impacts of legislative bans and restrictions on human exposure to these compounds.

Methods: Concentrations of PCBs and 17 PCDD/Fs were measured in 16 pools of human milk collected from 92 Irish primiparas participating in the Irish EPA-funded ELEVATE project between October 2016 and April 2018, using Gas-Chromatography coupled with Mass spectrometry.
\end{abstract}


Results: The geometric mean upper bound concentration of 16 pooled human milk samples [PCDD/Fs + dioxin-like (dl)-PCB TEQ; $4.5 \mathrm{ng} \mathrm{kg}^{-1}$ lipid weight] are on the lower end of those reported internationally. WHO-TEQ PCDD/Fs $+\mathrm{dl}-\mathrm{PCB}$ are significantly lower $(P<0.005)$ compared to those reported in the previous Irish human milk studies in 2010 and 2002.

Conclusion: Detected concentrations in this study are comparable to those reported for less industrialised countries in the last WHO/UNEP global surveys for PCDD/Fs. This downward temporal trend likely reflects the impact of regulatory bans and restrictions on the emissions of dioxins and PCBs. While mean upper bound WHO PCDD/F PCB TEQ concentrations are lower than those estimated by EFSA to be associated with adverse health effects in children age 9, maximum upper bound concentrations do exceed EFSA reference concentrations. While the positive health benefits of breastfeeding to both mother and child significantly outweigh potential adverse health effects at reported concentrations, continued action to reduce human body burdens of dioxins and PCBs is required.

Keywords: Dioxins, PCBs, POPs, temporal trends, human biomonitoring, breast milk

\section{INTRODUCTION}

Polychlorinated dibenzo-p-dioxins and polychlorinated dibenzofurans (PCDD/Fs), commonly referred to as dioxins and polychlorinated biphenyls (PCBs), are highly toxic persistent organic chemicals capable of resisting photolytic, biological, and chemical degradation ${ }^{[1]}$. Generated mostly from anthropogenic activity, $\mathrm{PCDD} / \mathrm{Fs}$ are produced as a by-product of numerous industrial and combustion processes, including the manufacture of pesticides and herbicides, chlorine bleaching of paper and waste incineration ${ }^{[1]}$. Emissions from such anthropogenic activities substantially outweigh those from natural sources such as forest fires and volcanic eruptions $s^{[1,2]}$. PCB manufacture commenced in 1929 , finding a variety of uses, including as heat exchange fluids in electrical transformers and as additives in paints and adhesives, until manufacture and new uses were banned across the globe in the late 1970 s and early $1980 \mathrm{~s}^{[1-4]}$. There are 209 PCB congeners which are divided into two groups based on their toxicity. PCBs which display similar toxicological effects to $\mathrm{PCDD} / \mathrm{Fs}$ due to their ability to adopt a co-planar structure and interact with Aryl hydrocarbon (AH) receptors, are referred to as dioxin-like PCBs. Binding to the AH receptors induces CYP1 drug metabolising enzymes, and this binding is critical for dioxin-like PCBs' toxic action ${ }^{[3]}$. Data on non-dioxin like PCBs are often reported as the sum of six PCB congeners (PCB 28, 52, 101, 138, 153, 180) or as the sum of six congeners plus PCB $118^{[5]}$.

Environmental contamination with PCDD/Fs and PCBs arises as a result of point pollution sources and long-range transportation, resulting in their ubiquitous distribution in the environment, including locations distant from the original source ${ }^{[0,7]}$. Extensive stores of $\mathrm{PCB}$ and dioxin containing equipment and/or waste still remain across the globe, which must be managed or treated in an environmentally sound manner so as to avoid further environmental contamination ${ }^{[4]}$.

Human exposure to PCDD/Fs and PCBs has been linked to a range of both acute and chronic human health effects, including chloracne, immunotoxicity, reproductive, neurodevelopmental, and dioxins are carcinogenic $^{[1]}$. There has been considerable public, scientific, and regulatory debate, and concern over the adverse impact of PCDD/Fs and PCBs on human health and on the environment, which has resulted in their inclusion under Annexes A (PCBs) and C (PCDD/Fs) of the UNEP Stockholm Convention ${ }^{[4]}$. Due to the propensity of $\mathrm{PCDD} / \mathrm{Fs}$ and $\mathrm{PCB}$ s to bio-accumulate, the diet, in particular the ingestion of animalbased produce, is recognised as being the main non-occupational human exposure pathway. 
Acknowledging the importance of the dietary exposure pathway for dioxin and dioxin-like PCBs, in 2001, the European Commission introduced a strategy to take further action to prevent environmental and adverse health effects from these compounds. This strategy included the introduction of a Tolerable Weekly Intake (TWI) value of $14 \mathrm{pg}$ toxic equivalent (WHO-TEQ)/kg body weight. At that time, daily average European dietary intake was between 1 and $3 \mathrm{pg}$ (WHO-TEQ)/kg body weight, and thus a substantial proportion of the EU population exceeded the TWI ${ }^{[8]}$.

An assessment of Irish adult dietary exposure to Dioxins and Indicator PCBs from data collected in a biomonitoring programme between 2003-10 and food consumption between 2008-10 concluded that dietary exposure of Irish adults was lower than the European average and did not exceed the TWI for dioxins or the NOAEL for PCBs ${ }^{[0]}$.

In 2018, the European Commission, on the advice of the EFSA CONTAM Panel, revised the TWI downward to $2 \mathrm{pg}$ (WHO-TEQ) $\mathrm{kg}^{-1}$ body weight/week, to take account of new epidemiological and animal data and protect against reproductive health effects in males. EFSA reported that average and high dietary exposures across the EU were up to five and fifteen times higher than the new TWI in adolescents, adults, and the elderly ${ }^{[10]}$.

WHO has planned to conduct an International re-evaluation of the current Toxic Equivalency Factors (WHO-TEFs) used to estimate the total dioxin-like activity of mixtures of PCDDs, PCDFs and PCBs in 2022 , following concerns that the current TEFs may overestimate the toxicity of some PCBs such as PCB$126^{[11]}$.

Since 1987, WHO has coordinated a global monitoring programme for PCDD/Fs and PCBs in human milk samples ${ }^{[12,13]}$. The programme aims to evaluate the impact of restrictions and bans implemented under the Stockholm Convention on human exposure and to examine global temporal and spatial trends in exposure. Fifty-two countries, including Ireland, participate in this programme. Results from the most recent, fourth and fifth surveys (2005-2010) show higher concentrations in more industrialised countries, with the highest values reported in Europe. Comparisons between results from the fourth and fifth surveys and those from the third survey are indicative of a downward trend in exposure; however, in all countries studied, total toxic equivalency (TEQ) concentrations of PCDD/Fs and PCBs combined were one to two orders of magnitude higher than levels considered toxicologically relevant for the foetus and breastfed infants, indicating a requirement for continued action to reduce human exposure ${ }^{[14]}$.

Prior to this study, the most recent study of PCDD/Fs and PCBs in Irish human milk was based on samples collected in $2010^{[15]}$. Measured concentrations were compared to results from Irish human milk samples included in the third WHO survey that were collected in $2002^{[12]}$. Reported concentrations in 2010 (sum of WHO-TEQ, $9.66 \mathrm{pg} \mathrm{g}^{-1}$ fat $)$ were lower than values reported in $2002\left(\approx 13.0 \mathrm{pg} \mathrm{g}^{-1}\right.$ fat total WHO TEQ for urban pools and 8.9 and $11.6 \mathrm{pg} \mathrm{g}^{-1}$ fat total WHO TEQ for rural pools), and consistent with some of the lower exposure data reported for Europe.

This study report concentrations of PCDD/Fs and PCBs in 16 pooled samples of Irish human milk collected from 92 Irish primiparas between October 2016 and 2018. This study was designed to facilitate the elucidation of temporal trends in human exposure to PCDD/Fs and PCBs since the last Irish human milk survey in 2010 and evaluate the impacts of legislative bans and restrictions on human exposure to these compounds. 


\section{EXPERIMENTAL}

\section{Human milk sample collection and pooling}

Samples analysed in this study were collected between October 2016 and April 2018 as part of an Irish EPA funded research project (ELEVATE, reference 2016-HW-MS-8). The samples have previously been analysed for concentrations of brominated flame retardants ${ }^{[16]}$ and Perfluoroalkyl substances ${ }^{[17]}$. The study population, approach to recruitment, sampling, and sample pooling are reported in detail in Wemken et al. ${ }^{[16]}$, 2020. In brief, study recruitment and sampling protocols, adhered (with minor deviations) to WHO UNEP guidelines for developing a national protocol for measurement of POPs in human milk ${ }^{[13]}$ and the study protocols of Pratt et al. ${ }^{[15]}, 2012$. Comparability of study design with the study of Pratt et al. ${ }^{[15]}$ (2012) was important to facilitate elucidation of temporal trends in concentrations of PCDD/Fs and PCBs in human milk in Ireland. Study protocols were approved by the Clinical Research Ethics Committee of the University Hospital Galway (Ref: C.A. 1578) and the Research Ethics Committee of the Coombe Women and Infants University Hospital in Dublin (No. 30-2016).

Mothers were recruited while attending breastfeeding clinics in two Irish maternity hospitals, who also participated in the Pratt et al. ${ }^{[15]}, 2012$, namely University Hospital Galway (UHG) and the Coombe Women and Infants University Hospital (Coombe), Dublin. Participants chosen had to meet the following criteria: (1) primiparas exclusively nursing one infant; (2) in good health; (3) 3-8 weeks postpartum; (4) residing in their current address for at least 5 years previously; and (5) 40 years old or younger (in contrast to the WHO guidance of less than 30 years old, this criterion was amended to less than 40 years old for the study, as $65 \%$ of Irish mothers are between 30-40 years old $\left.{ }^{[18]}\right)$. All eligible candidates completed consent forms and provided contextual information via a questionnaire.

Approximately 30-60 mL of milk were collected from each individual donor in clean polypropylene containers and stored at $-18{ }^{\circ} \mathrm{C}$ before pooling. The total number of samples collected was 92 (UHG $=59$ and $\mathrm{CIMH}=33$ ). Samples were thawed and homogenised prior to pooling. Data provided from the questionnaires were used to determine how each sample was pooled, with a summary of donor demographics per pool provided in supporting information [Supplementary Table SI-1]. There were a total of 16 sample pools prepared, pools were determined by the following factors: place of birth (e.g., Ireland, UK, EU, non-EU), place of residence for the previous 5 years (e.g., urban or rural etc.). Two pools were prepared on the basis of whether participants consumed fish at least twice a week. Each pool contained $30 \mathrm{~mL}$ aliquots of milk from each contributing donor (in fish-consumer pools, only $15 \mathrm{~mL}$ aliquots were used due to limited sample availability). The individual sample numbers per pool varied between 3 and 10. Pooled milk samples were freeze-dried at $-73{ }^{\circ} \mathrm{C}$ for approx. One hundred and twenty hours prior to analysis (using a VirTis Bench Top Pro BTP-3X100 freeze drier).

\section{Sample preparation of human milk}

Extraction and clean-up

Human milk sample extraction, extract purification/clean-up, and instrument analysis processes were undertaken at the State Laboratory, Backweston Lab Campus, Celbridge, Co. Kildare. Lipids were extracted from a $10 \mathrm{~g}$ portion of freeze-dried breast milk from each pool using pressurised liquid extraction (ASE 350, Dionex, Sunnyvale, California, USA), at $80{ }^{\circ} \mathrm{C}, 1500$ psi, and a solvent ratio of $62.5 \%$ hexane, $25 \%$ dichloromethane, and $12.5 \%$ methanol. Lipid content was determined gravimetrically (further details are provided in Supplementary Table SI-2).

$2.5 \mathrm{~g}$ of the extracted lipid was then spiked with a known quantity of internal standard (details are provided in Supplementary Table SI-3), $1 \mathrm{~mL}$ of hexane was added to aid loading the sample to the clean-up column. Clean-up and fractionation were carried out on a Miura GO-6HT sample clean-up system (Miura, Matsuyama, Ehime, Japan), using silica, alumina, and carbon columns. The samples were collected in two 
fractions, fraction A containing the Mono-ortho PCB, and Non-dioxin like PCB (MOPIP) congeners and fraction B containing the Dioxin and Non-ortho PCBs (DIOXNOP) congeners. Sample fractions were then concentrated, and reconstituted in either toluene (fraction B) or nonane (fraction A) (depending on fraction), and fortified with recovery standards (13C12-1,2,3,4 TCDD and 13C12-1,2,3,4,6,8,9 HpCDF).

Instrumental analysis of human milk samples

Samples were analysed for 2,3,7,8-chlorinated PCDD/Fs and non-ortho substituted PCBs (congeners 81, 77, 126 and 169) using a Thermo DFS system (Thermo Fisher Scientific, Bremen, Germany). GC programme; $90{ }^{\circ} \mathrm{C}$ for $3 \mathrm{~min}$, heat to $200{ }^{\circ} \mathrm{C}$ at $20^{\circ} \mathrm{C} / \mathrm{min}$, from $200{ }^{\circ} \mathrm{C}$ to $280{ }^{\circ} \mathrm{C}$ at $4{ }^{\circ} \mathrm{C} / \mathrm{min}$, hold $20 \mathrm{~min}$, from $280{ }^{\circ} \mathrm{C}$ to $300{ }^{\circ} \mathrm{C}$ at $5{ }^{\circ} \mathrm{C} / \mathrm{min}$, hold $8 \mathrm{~min}$. Samples were analysed for the mono-ortho chlorinated PCBs (congeners $123,118,114,105,167,156,157$ and 189) and indicator PCBs (congeners 28,101, 153, 138 and 180) on a Waters Autospec GC-HRMS system (Waters, Milford, Massachusetts, USA). GC programme; $110^{\circ} \mathrm{C}$ for $3 \mathrm{~min}$, heat to $200{ }^{\circ} \mathrm{C}$ at $20^{\circ} \mathrm{C} / \mathrm{min}$, from $200{ }^{\circ} \mathrm{C}$ to $300{ }^{\circ} \mathrm{C}$ at $4{ }^{\circ} \mathrm{C} / \mathrm{min}$, hold $10 \mathrm{~min}$. The GC column used for both analyses was a DB-5MS, $60 \mathrm{~m} \times 0.25 \mathrm{~mm} \times 0.25 \mathrm{~mm}$ (Agilent, Santa Clara, California, USA).

Analysis was completed using a validated method, and performed following the criteria laid out in EU Commission Regulation 2017/644, of 5th April 2017 $7^{[19]}$, with two masses measured for each of the 35 congeners of interest [Supplementary Table SI-4].

\section{Quality control and assurance}

All Dioxin sample analysis work is INAB accredited to ISO 17025 and was carried out in the State Laboratory, which is the National Reference Laboratory for persistent organic pollutants (POPs) in food and feed in Ireland. All batches included solvent blanks, solvent standards as system suitability/verification checks, and quality control material (either a certified reference material, or a previously analysed proficiency testing (PT) scheme sample. Method blanks were also included in the batches at regular intervals (further details are provided in Supplementary Table SI-5).

Reporting of Dioxin results - TEF concept

Concentrations of individual PCDD/Fs and dl-PCBs were expressed as a TEQ, calculated by multiplying the concentration of each individual target compound by the corresponding TEF published by WHO in $2005^{[20]}$ and provided as Supplementary Table SI-6. WHO-TEQs were calculated as upper bound concentrations, using the limit of quantification for the contribution of each non-quantified congener ${ }^{[2]}$. Summing of TEQ concentrations of all individual congeners for a given sample provided the sum TEQ concentration for that sample.

Statistical analysis was performed using SPSS Statistics for Window version 26. Concentration data were normally distributed, and a $t$-test was used to compare concentrations in the current study with previous data from 2010 and $2002^{[12,15]}$.

\section{Estimation of infant intake of PCDD/F and PCBs via breast milk}

In order to evaluate a nursing infant's dietary intake of PCDD/Fs and dl-PCBs, in this study, estimated daily intake values were calculated using Equation $(1)^{[1,022]}$ [Supplementary Table SI-7]:

$$
\text { EDI }\left(\text { pg-TEQ } 2005 \mathrm{~kg}^{-1} \text { body weight day }{ }^{-1}\right)=\frac{C x M}{W}
$$


where EDI is the estimated daily intake calculated for breastfed infants below 6 months of age (median age of three months was used as per EFSA, 2018); C geometric average PCDD/F and dl-PCB concentrations in the study groups ( $\mathrm{pg}-\mathrm{TEQ}_{2005} \mathrm{~g}^{-1}$ milk); $\mathrm{M}$ is the estimated average daily milk consumption $\left(\mathrm{g} \mathrm{day}^{-1}\right)$; and $\mathrm{W}$ is the mean body weight of a baby aged three months. Body weight of $6.1 \mathrm{~kg}$ and an average human milk intake of $800 \mathrm{~mL} \mathrm{day}^{-1}$, and high consumption of $1200 \mathrm{~mL} \mathrm{day}^{-1}$ were used $^{[10]}$. The median lipid content of the samples analysed was $3.47 \mathrm{~g}$ per $100 \mathrm{~mL}$ of breast milk, resulting in average and high lipid intakes of $27.76 \mathrm{~g} \mathrm{day}^{-1}$ and $41.64 \mathrm{~g} \mathrm{day}^{-1}$, respectively. Upper bound (UB) and lower bound (LB) geometric average $\mathrm{PCDD} / \mathrm{F}$ and $\mathrm{PCB}$ concentrations were used to calculate exposure intakes in pg TEQ $\mathrm{kg}^{-1}$ bw per day.

\section{RESULTS}

\section{Concentrations of PCDD/Fs, non-o-PCBs, and mono-ortho-PCBs in Irish human milk samples collected between 2016 and 2018}

Tables 1 and 2 respectively [Supplementary Table SI-8, Supplementary Figures SI-8.1-SI-8.9] list concentrations of PCDD/Fs and dl-PCBs and indicator PCBs (expressed as upper bound concentrations per $\mathrm{kg}$ lipid weight), measured in the 16 pools of human milk collected in this study. An analysis of individual $\mathrm{PCDD} / \mathrm{F}$ congener concentrations, showed that OCDD was presented in the highest concentration followed by $2,3,4,7,8$ - PeCDF and $1,2,3,4,6,7,8$ - HpCDD, similar to the profile reported in the last Irish study of samples collected between 2009 and $2010^{[12]}$. OCDD, 1,2,3,4,6,7,8-HpCDD and 1,2,3,6,7,8-HxCDD are also among the dominant congeners reported by other researchers for previous studies on human milk ${ }^{[2,2,23]}$. The dominant dl-PCB congeners reported in this study were PCB 118 followed by PCB-156, also consistent with previous studies ${ }^{[1,22,23]}$. PCB-153 followed by PCB-180 were the dominant Indicator PCBs detected in this study, similar to the pattern reported in Pratt et al ${ }^{[15]}, 2012$, and Focant et al. ${ }^{[23]}, 2013$.

The sum of WHO TEQs (PCDD/F + dl-PCB) concentrations ranged from 3.4-8.0 ng $\mathrm{kg}^{-1}$ lipid $(\mathrm{GM}=$ $4.5 \mathrm{ng} \mathrm{kg}^{-1}$ lipid), overall, PeCDD congeners made the greatest contribution to $\mathrm{WHO}^{\mathrm{TEQ}} \mathrm{Q}_{05}(38 \%)$ followed by PCBs (33\%) and PCDFs (29\%) congeners. An analysis of the congener profiles showed that 1,2,3,7,8PeCDD, PCB-126, and 2,3,4,7,8-PeCDF were the dominant congeners $(24 \%, 25 \%$, and $22 \%$ of total WHO TEQs (PCDD/F + dl-PCB) consistent with Pratt et al. $.^{[15]}, 2012$, Hernández et al. ${ }^{[22]}, 2020$, and Focant et al. ${ }^{[23]}$, 2013.

\section{DISCUSSION}

\section{Comparison of PCDD/Fs, non-ortho-PCBs, and mono-ortho-PCBs levels in Irish human milk samples collected between 2016 and 2018 to previous surveys}

Table 3 (reproduced from Hernández et al. ${ }^{[22]}$, 2020) compares concentrations of $\sum \mathrm{PCDD} / \mathrm{Fs}$ and dl-PCBs in human milk reported in this study with concentrations reported internationally over the period 2012 to 2020. Irish concentrations (GM PCDD/Fs + dl-PCB TEQ; $4.5 \mathrm{ng} \mathrm{kg}^{-1}$ ) are comparable to studies reporting lower concentrations. Geometric mean values in this study (2016-18) reported by Hernández et al. $.^{[22]}, 2020$, (GM PCDD/Fs + dl-PCB TEQ; $4.42 \mathrm{ng} \mathrm{kg}^{-1}$ ) in the Spanish BETTERMILK study for samples collected in 2015. Irish values in this study (PCDD/Fs + dl-PCB TEQ GM $4.5 \mathrm{ng} \mathrm{kg}^{-1}$ ) are comparable to values reported in the fourth and fifth WHO UNEP survey for less industrialised countries and countries in the southern hemisphere ${ }^{[14]}$ and are much lower than those reported for mainland Europe including Italy (AM value; $\left.13.4 \mathrm{ng} \mathrm{kg}^{-1}\right)^{[26]}$ and France $\left(10.74 \mathrm{ng} \mathrm{kg}^{-1}\right)^{[31]}$. They are also less than those reported in the last Irish study for samples collected in 2009-2010 (AM value; $\left.9.66 \mathrm{ng} \mathrm{kg}^{-1}\right)^{[15]}$. Concentrations of the dominant indicator PCBs, (PCB-153; $11.0 \mu \mathrm{g} \mathrm{kg}^{-1}$ PCB-180; $6.4 \mu \mathrm{g} \mathrm{kg}^{-1}$, PCB-138; $5.9 \mu \mathrm{g} \mathrm{kg}^{-1}$ ) are slightly lower than those reported in the last Irish human milk study in 2010 (PCB-153; $12.6 \mu \mathrm{g} \mathrm{kg}^{-1}$ PCB-180; $7.4 \mu \mathrm{g} \mathrm{kg}^{-1}$, PCB-138; $\left.6.9 \mu \mathrm{g} \mathrm{kg}^{-1}\right)^{[15]}$ and significantly lower than concentrations reported in the French Elfe Pilot study in 2007 (PCB-153; $83.04 \mu \mathrm{g} \mathrm{kg}^{-1}$ PCB-180; $48.34 \mu \mathrm{g} \mathrm{kg}^{-1}$, PCB-138; $\left.39.97 \mu \mathrm{g} \mathrm{kg}^{-1}\right)^{[23]}$. 
Table 1. Descriptive statistics for $\mathrm{PCDD} / \mathrm{F}$ and $\mathrm{PCB}$ concentrations (ng kg ${ }^{-1}$ lipid weight) and WHO-TEQ ${ }_{05}$ (upper bound concentrations $\mathrm{n} \mathrm{kg}^{-1}$ lipid weight) in 16 pooled human milk samples

\begin{tabular}{|c|c|c|c|c|c|}
\hline & Arithmetic mean & Geometric mean & Median & Min & Max \\
\hline \multicolumn{6}{|l|}{$\mathrm{PCDD} / \mathrm{F}$} \\
\hline $2,3,7,8-T C D F$ & 0.32 & 0.31 & 0.30 & 0.18 & 0.59 \\
\hline $1,2,3,7,8-P e C D F$ & 0.25 & 0.22 & 0.22 & 0.11 & 0.49 \\
\hline $2,3,4,7,8-P e C D F$ & 3.5 & 3.3 & 3.0 & 2.3 & 6.6 \\
\hline $1,2,3,4,7,8-H x C D F$ & 0.92 & 0.88 & 0.86 & 0.63 & 1.8 \\
\hline $1,2,3,6,7,8-H x C D F$ & 0.96 & 0.91 & 0.90 & 0.63 & 1.8 \\
\hline $2,3,4,6,7,8-H \times C D F$ & 0.52 & 0.49 & 0.48 & 0.31 & 1.0 \\
\hline $1,2,3,7,8,9-H x C D F$ & 0.10 & 0.10 & 0.11 & 0.06 & 0.12 \\
\hline $1,2,3,4,6,7,8-H p C D F$ & 0.64 & 0.62 & 0.64 & 0.39 & 1.0 \\
\hline $1,2,3,4,7,8,9-H p C D F$ & 0.08 & 0.08 & 0.08 & 0.06 & 0.1 \\
\hline OCDF & 0.09 & 0.09 & 0.09 & 0.09 & 0.09 \\
\hline $2,3,7,8-T C D D$ & 0.36 & 0.35 & 0.33 & 0.27 & 0.61 \\
\hline $1,2,3,7,8-P e C D D$ & 1.1 & 1.1 & 0.96 & 0.78 & 2.0 \\
\hline $1,2,3,4,7,8-H x C D D$ & 0.43 & 0.41 & 0.37 & 0.28 & 0.68 \\
\hline $1,2,3,6,7,8-H \times C D D$ & 2.1 & 2.0 & 1.9 & 1.4 & 3.4 \\
\hline $1,2,3,7,8,9-H x C D D$ & 0.52 & 0.50 & 0.45 & 0.36 & 0.8 \\
\hline $1,2,3,4,6,7,8-H p C D D$ & 2.5 & 2.4 & 2.3 & 1.5 & 4.2 \\
\hline$O C D D$ & 20 & 19 & 17 & 14 & 40 \\
\hline WHO-PCDD/F-TEQ UB ${ }^{a}$ & 3.1 & 3.0 & 2.8 & 2.3 & 5.6 \\
\hline \multicolumn{6}{|l|}{ Non-Ortho-PCBs/ dl-PCBs ${ }^{b}$} \\
\hline PCB-81 & 0.85 & 0.82 & 0.78 & 0.61 & 1.5 \\
\hline PCB-77 & 5.1 & 4.5 & 5.3 & 2.1 & 11 \\
\hline PCB-126 & 12 & 11 & 11 & 8.5 & 19 \\
\hline PCB-169 & 6.8 & 6.5 & 6.2 & 4.4 & 11 \\
\hline WHO-Non-Ortho-PCB-TEQ UB ${ }^{\text {a }}$ & 1.4 & 1.3 & 1.3 & 1.0 & 2.2 \\
\hline \multicolumn{6}{|l|}{ Mono-Ortho-PCBs/ dl-PCBs } \\
\hline PCB-123 & 35 & 34 & 34 & 24 & 52 \\
\hline PCB-118 & 2400 & 2400 & 2200 & 1700 & 380 \\
\hline PCB-114 & 130 & 120 & 110 & 85 & 220 \\
\hline PCB-105 & 550 & 540 & 500 & 410 & 810 \\
\hline PCB-167 & 350 & 320 & 310 & 190 & 700 \\
\hline PCB-156 & 1000 & 960 & 830 & 650 & 2600 \\
\hline PCB-157 & 220 & 210 & 180 & 140 & 390 \\
\hline PCB-189 & 93 & 83 & 71 & 52 & 270 \\
\hline WHO-Mono-Ortho-PCB-TEQ UB ${ }^{a}$ & 0.15 & 0.14 & 0.13 & 0.10 & 0.26 \\
\hline WHO-PCB-TEQ UB ${ }^{a}$ & 1.5 & 1.5 & 1.4 & 1.1 & 2.4 \\
\hline WHO-PCDD/F-PCB-TEQ UB ${ }^{\text {a }}$ & 4.6 & 4.5 & 4.1 & 3.4 & 8.0 \\
\hline
\end{tabular}

aUB: Upper bound; ${ }^{b}$ dl-PCBs: dioxin-like PCBs.

Highest WHO TEQs (PCDD/F + dl-PCB) concentrations are reported for Pool $6\left(\mathrm{GM} 8.01 \mathrm{ng} \mathrm{kg}^{-1}\right)$ and lowest concentrations for Pool 8 ( GM $\left.3.42 \mathrm{ng} \mathrm{kg}^{-1}\right)$. Donors to both pools were recruited from the west of Ireland and lived in suburban (Pool 6), urban, and rural locations (Pool 8). The dietary habits of the donors to both pools were similar (a varied diet and were all fish consumers (fish consumed included sea fish, salmon, cod, and trout). The median donor age for Pool 6 is higher than that of Pool 8 (37 and 33 years, respectively). Correlations between the concentration of persistent organic chemicals such as dioxins in 
Table 2. Descriptive statistics for Indicator PCBs concentrations ( $\mathrm{g} \mathrm{kg}^{-1}$ lipid weight $\mathrm{UB}^{\mathrm{a}}$ ) in 16 pooled human milk samples

\begin{tabular}{|c|c|c|c|c|c|}
\hline Indicator-PCBs & Arithmetic mean & Geometric mean & Median & Min & Max \\
\hline PCB-28 & 0.44 & 0.43 & 0.43 & 0.35 & 0.63 \\
\hline PCB-52 & 0.13 & 0.13 & 0.12 & 0.09 & 0.21 \\
\hline PCB-101 & 0.20 & 0.19 & 0.20 & 0.14 & 0.29 \\
\hline PCB-153 & 11 & 10 & 8.9 & 6.4 & 31 \\
\hline PCB-138 & 5.9 & 5.5 & 4.9 & 3.8 & 16 \\
\hline PCB-180 & 6.4 & 5.6 & 4.7 & 3.1 & 22 \\
\hline$\sum$ indicator $\mathrm{PCBs} \mathrm{UB}^{\mathrm{a}}$ & 24 & 22 & 19 & 14 & 69 \\
\hline
\end{tabular}

aUB: Upper bound.

Table 3. Comparison of PCDD/F and dI-PCB TEQ concentrations (pg TEQ $\mathrm{g}^{-1}$ lipid weight) detected in human milk in this study and comparator surveys elsewhere (Table adapted from Hernández et al. $\left.{ }^{[22]}, 2020\right)$.

\begin{tabular}{|c|c|c|c|c|c|}
\hline Ref. & Period & Country & $n$ & $\sum$ PCDD/Fs & $\sum \mathrm{PCDD} / \mathrm{Fs}+\mathrm{dl}-\mathrm{PCBs}$ \\
\hline Current study & $2016-2018$ & Ireland & 92 & $3.1^{a, b}$ & $4.63^{\mathrm{a}, \mathrm{b}}$ \\
\hline Hernández et al. ${ }^{[22]},(2020)$ & 2015 & Valencian Region (Spain) & 75 & $2.71^{a, c}$ & $4.42^{\mathrm{a}, \mathrm{c}}$ \\
\hline Schuhmacher et al. ${ }^{[25]}$, (2019) & 2017 & Tarragona (Spain) & 20 & $2.26^{\mathrm{a}, \mathrm{b}}$ & - \\
\hline Roberto et al. ${ }^{[26]},(2018)$ & 2010 & Italy & 20 & $7.13^{b, d}$ & $13.4^{b, d}$ \\
\hline Chen et al. ${ }^{[27]},(2018)$ & $2013-2016$ & China & 25 & $2.44^{\mathrm{a}, \mathrm{c}}$ & - \\
\hline Hue et al. ${ }^{[28]},(2018)$ & 2014-2015 & Vietnam & 36 & $10.2^{\mathrm{a}, \mathrm{b}}$ & - \\
\hline Ae et al. ${ }^{[29]},(2018)$ & 1998-2015 & Japan & 1194 & $10.95^{a, b}$ & $17.00^{a, b}$ \\
\hline Rawn et al. ${ }^{[30]},(2017)$ & 2008-2011 & Canada & 298 & $4.9^{\mathrm{a}, \mathrm{b}}$ & $6.3^{\mathrm{a}, \mathrm{b}}$ \\
\hline Antignac et al. ${ }^{[31]},(2016)$ & $2011-2014$ & France & 96 & $6.16^{\mathrm{a}, \mathrm{c}}$ & $10.74^{\mathrm{a}, \mathrm{c}}$ \\
\hline Antignac et al. ${ }^{[31]},(2016)$ & 1997-2002 & Denmark & 438 & $13.01^{\mathrm{a}, \mathrm{c}}$ & $19.86^{\mathrm{a}, \mathrm{c}}$ \\
\hline Antignac et al. ${ }^{[31]},(2016)$ & 1997-2002 & Finland & 22 & $8.79^{a, c}$ & $13.62^{a, c}$ \\
\hline Zhang et al. ${ }^{[32]},(2016)$ & 2011 & China & 1760 & $4.9^{b, d}$ & $6.7^{\mathrm{b}, \mathrm{d}}$ \\
\hline Lu et al. ${ }^{[33]},(2015)$ & 2011-2012 & China & 150 & $5.4^{a, b}$ & $8.3^{\mathrm{a}, \mathrm{b}}$ \\
\hline Giovannini et al. ${ }^{[24]}$, (2014) & $2007-2008$ & Italy & 95 & $6.46^{\mathrm{a}, \mathrm{b}}$ & - \\
\hline Focant et al. ${ }^{[23]}, 2013$ & 2007 & France & 44 & $9.58^{a, c}$ & $17.81^{\mathrm{a}, \mathrm{c}}$ \\
\hline Croes et al. ${ }^{[34]},(2013)$ & $2009-2010$ & Belgium & 84 & $6.9^{a, c}$ & $10.7^{\mathrm{a}, \mathrm{c}}$ \\
\hline Wong et al. ${ }^{[35]},(2013)$ & 2009 & China & 137 & $7.48^{\mathrm{b}, \mathrm{d}}$ & $11.27^{\mathrm{b}, \mathrm{d}}$ \\
\hline Pratt et al. ${ }^{[15]},(2012)$ & 2010 & Ireland & 109 & $6.32^{b, d}$ & $9.66^{b, d}$ \\
\hline
\end{tabular}

${ }^{\mathrm{a}}$ TEQ 2005; ${ }^{\mathrm{b}}$ mean; ${ }^{\mathrm{c}}$ geometric mean; ${ }^{\mathrm{d}} \mathrm{TEQ} 1998, n=$ samples.

human milk and donor age are likely and have been reported in the literature ${ }^{[2,24]}$. However, in this study, donor samples were pooled, and so an analysis of associations between concentration and age of donor was not possible.

In terms of total TEQ (PCDD/F + dl-PCB) both pools are characterised by four dominant congeners, the percentage contribution of each congener to TEQ only differs slightly suggesting similar exposure sources. $1,2,3,7,8$-PeCDD is the dominant (25\%) congener in Pool 6 (followed by $2,3,4,7,8$-PeCDF > PCB-126 > 2,3,7,8-TCDD) whereas PCB-126 is the dominant congener (25\%) in Pool 8 (followed by 1,2,3,7,8-PeCDD > 2,3,4,7,8-PeCDF $>2,3,7,8-\mathrm{TCDD})$.

In contrast to total TEQ concentrations (PCDD/F + dl-PCB), for which Pools 6 and 8 had the highest and lowest concentrations respectively, the highest concentrations of indicator PCBs are found in Pool 9 $\left(69 \mathrm{ng} \mathrm{kg}^{-1}\right)$, followed by Pool $1\left(36 \mathrm{ng} \mathrm{kg}^{-1}\right)$. Pool 6 ranks third in terms of the highest indicator PCB 
concentrations ( $30 \mathrm{ng} \mathrm{kg}^{-1}$ ), and Pool 8 has one of the lower concentrations (16 $\mathrm{ng} \mathrm{kg}^{-1}$ ). Both Pools 1 and Pool 9 were two of the four pools (alongside Pools 10 and 11) composed of donors born outside of Ireland. Factors including diet and the proportion of donors born outside of Ireland within a given pool may explain differences in concentration.

\section{Temporal trends in PCDD/F and PCB TEQ concentrations in Irish human milk}

Concentrations of individual PCDD/Fs, dioxin-like PCBs and indicator PCBs in the current study $(n=16$ pools) were compared with those reported in the last Irish study from $2010(n=11 \text { pools })^{[15]}$ and with Irish data from 2002 $(n=4 \text { pools })^{[12]}$ [Tables 4 and 5, Supplementary Tables SI-8.1-SI-8.4, Figure 1, Supplementary Figures SI-8.6-SI-8.9]. A full $t$-test comparison was possible to compare data from the 2010 survey with the current study. However, due to the limited pool size of the 2002 survey $(n=4)$, only a comparison of average concentrations was possible with this earliest study.

An examination of the temporal trend over the period 2002 to 2010 and from 2010 to 2016-18 shows a decreasing trend in WHO-PCDD/F-PCB-TEQ, consistent with other international studies and results from WHO/UNEP global surveys ${ }^{[1,23,27]}$, reflecting the positive impact of regulatory measures restricting and banning the use of persistent organic chemicals on human exposure ${ }^{[36]}$.

Concentrations of WHO-TEQ PCDD/F + dl-PCB in 2016-18 have declined by $>43 \%(P<0.005)$ since the last Irish study in 2010, reported concentrations in 2016-18 are $>51 \%$ lower than the concentrations reported in 2002 (WHO-TEQ PCDD/F + dl-PCB $9.5 \mathrm{ng} \mathrm{kg}^{-1}$ lipid weight in 2002, $8.1 \mathrm{ng} \mathrm{kg}^{-1}$ lipid weight in 2010 vs. $4.6 \mathrm{ng} \mathrm{kg}^{-1}$ lipid weight in 2016-18) [Figure 1]. This decline in concentrations has been accompanied by a shift in the contribution of PCDDs relative to PCDFs and PCBs, to the total WHO-TEQ PCDD/F + dlPCB concentration. The contribution of PCDFs has increased from $24 \%$ in 2010 to $29 \%$ in $2016-18$, while the contributions of PCDDs and PCBs have dropped from 41 to $39 \%$ and 35 to $33 \%$, respectively [Figure 2].

When compared to 2010 data, the percentage decrease in concentrations of individual PCDDs ranges from $48 \%-57 \%$, while the percentage decrease in concentrations of individual PCDFs ranges from $31 \%-93 \%$, in line with those observed by Focant et al. ${ }^{[23]}$, for French human milk surveys over the period 1998-99 and in 2007. In the last human biomonitoring survey in 2010, concentrations of many individual PCDFs and some dl-PCBs (PCB-77, PCB-126) have unchanged or increased slightly since 2002, however, results from this current study show that concentrations of all congeners (apart from 1,2,3,7,8,9-HxCDF) have decreased since 2010. Concentrations of 2,3,4,7,8-PeCDF are significantly lower $(P<0.001)$ in 2016-18 compared to values reported in 2010. In 2010, 2,3,4,7,8-PeCDF accounted for $82 \%$ of the total WHO-TEQ for PCDFs, however, in the current study, it contributes $78 \%$ of the total PCDF TEQ and indicates a statistically significant decrease $(P<0.001)$. Concentrations of $1,2,3,4,6,7,8$ - HpCDF have decreased by $68 \%$ since 2010 , others such as $2,3,4,6,7,8-\mathrm{HxCDF}$ have decreased by $93 \%$ since 2010 , however concentrations of $1,2,3,4,7,8,9$-HpCDF remain unchanged since 2010 but are $50 \%$ lower than values reported in 2002 . As expected, greater decreases are observed when comparing concentrations in the current study with those reported in 2002, e.g., congeners such as OCDF have dropped by $88 \%$ and $2,3,4,6,7,8-\mathrm{HxCDF}$ by $89 \%$.

Apart from PCB-77 (significantly higher in 2016-18 $P<0.005$ ), concentrations of dioxin-like PCBs are significantly lower in 2016-18, decreasing by $41 \%$ and $46 \%$ for non-ortho and mono-ortho PCBs, respectively, since 2010. Concentrations of most individual congeners have decreased from between $15 \%$ and 55\% since 2010, with the greatest decreases observed for concentrations of PCB-169 since 2010 (56\%) and since $2002(63 \%)$. In contrast, concentrations of PCB-77 have increased by $65 \%$ over the same period. 
Table 4. Comparison of arithmetic mean concentrations ( $\mathrm{ng} \mathrm{kg}^{-1}$ lipid weight) of individual PCDD/F and dioxin-like PCB congeners in the current study (2016-18) and previous Irish human milk surveys in 2002 and 2010 [Pratt et al. ${ }^{[15]}$, (2012)]

\begin{tabular}{|c|c|c|c|}
\hline$P C D D / F$ & $\begin{array}{l}2002 \\
(n=4 \text { pools })\end{array}$ & $\begin{array}{l}2010 \\
(n=11 \text { pools })\end{array}$ & $\begin{array}{l}2016-18 \\
(n=16 \text { pools })\end{array}$ \\
\hline $2,3,7,8-T C D F$ & 0.32 & 0.55 & 0.32 \\
\hline $1,2,3,7,8-P e C D F$ & 0.16 & 0.38 & 0.25 \\
\hline $2,3,4,7,8-P e C D F$ & 4.6 & 5.1 & 3.5 \\
\hline $1,2,3,4,7,8-H x C D F$ & 1.3 & 1.5 & 0.92 \\
\hline $1,2,3,6,7,8-H x C D F$ & 1.3 & 1.5 & 0.96 \\
\hline $2,3,4,6,7,8-H \times C D F$ & 0.54 & 0.89 & 0.52 \\
\hline $1,2,3,7,8,9-H \times C D F$ & 0.07 & 0.06 & 0.1 \\
\hline $1,2,3,4,6,7,8-H p C D F$ & 1.8 & 2.0 & 0.64 \\
\hline $1,2,3,4,7,8,9-\mathrm{HpCDF}$ & 0.04 & 0.08 & 0.08 \\
\hline OCDF & 0.44 & 0.17 & 0.09 \\
\hline $2,3,7,8-T C D D$ & 1.0 & 0.67 & 0.36 \\
\hline $1,2,3,7,8-P e C D D$ & 2.7 & 1.9 & 1.1 \\
\hline $1,2,3,4,7,8-H \times C D D$ & 1.7 & 0.86 & 0.43 \\
\hline $1,2,3,6,7,8-H x C D D$ & 8.1 & 4.7 & 2.1 \\
\hline $1,2,3,7,8,9-H x C D D$ & 2.0 & 0.97 & 0.52 \\
\hline $1,2,3,4,6,7,8-H p C D D$ & 12 & 5.5 & 2.5 \\
\hline$O C D D$ & 63 & 40 & 20 \\
\hline WHO-PCDD/F-TEQ UB ${ }^{a}$ & 6.7 & 5.3 & 3.1 \\
\hline \multicolumn{4}{|l|}{ Non-ortho-PCB/ dl-PCB } \\
\hline PCB-81 & 1.3 & 1.0 & 0.85 \\
\hline PCB-77 & 3.1 & 3.1 & 5.1 \\
\hline PCB-126 & 20 & 21 & 12 \\
\hline PCB-169 & 18 & 15 & 6.8 \\
\hline WHO-Non-Ortho-PCB-TEQ UB ${ }^{b}$ & 2.5 & 2.6 & 1.4 \\
\hline \multicolumn{4}{|l|}{ Mono-ortho-PCB/dl-PCBc UB ${ }^{b}$} \\
\hline PCB-123 & 29 & 47 & 35 \\
\hline PCB-118 & 4700 & 4200 & 2400 \\
\hline PCB-114 & 250 & 230 & 130 \\
\hline PCB-105 & 1100 & 940 & 550 \\
\hline PCB-167 & 770 & 460 & 350 \\
\hline PCB-156 & 2300 & 1600 & 1000 \\
\hline PCB-157 & 450 & 350 & 220 \\
\hline PCB-189 & 180 & 150 & 93 \\
\hline WHO-Mono-Ortho-PCB-TEQ UB ${ }^{b}$ & 0.29 & 0.24 & 0.14 \\
\hline WHO-PCDD/F-PCB-TEQ UB ${ }^{\text {b }}$ & 9.5 & 8.1 & 4.6 \\
\hline
\end{tabular}

${ }^{\mathrm{a} U B}$ : upper bound; ${ }^{\mathrm{b}} \mathrm{dl}-\mathrm{PCB}$ : dioxin-like PCBs.

Concentrations of $\sum$ indicator PCBs have declined by $42 \%$ since 2010 and are $55 \%$ lower than values reported in 2002. Individual congeners such as PCB- 28 has decreased by $56 \%$ while PCB- 52 has increased by $44 \%$ over the same period.

Concentrations of WHO-TEQ PCDD/F+ dl-PCB in both Dublin and Galway pools are significantly lower $(P<0.001)$ in 2016-18 than in 2010 and do not display any regional variations. Similar declines in concentrations (over the period 2010-2016-18) of WHO-TEQ PCDD/F + dl-PCB are observed in both 
Table 5. Arithmetic mean concentrations $(\times \mathrm{g} / \mathrm{kg})$ of indicator PCB congeners detected in the current study (2016-18) and in previous Irish human milk surveys in 2002 and 2010 [Pratt et al. $\left.{ }^{[15]},(2012)\right]$

\begin{tabular}{llll}
\hline Indicator-PCB & $\begin{array}{l}\mathbf{2 0 0 2} \text { mean } \\
(\boldsymbol{n}=\mathbf{4} \text { pools })\end{array}$ & $\begin{array}{l}\mathbf{2 0 1 0} \text { mean } \\
(\boldsymbol{n}=\mathbf{1 1} \text { pools })\end{array}$ & $\begin{array}{l}\mathbf{2 0 1 8} \text { mean } \\
(\boldsymbol{n}=\mathbf{1 6} \text { pools })\end{array}$ \\
\hline$P C B-28$ & 1.1 & 1.0 & 0.44 \\
$P C B-52$ & 0.19 & 0.09 & 0.13 \\
$P C B-101$ & 0.35 & 0.2 & 0.2 \\
$P C B-153$ & 19 & 17 & 11 \\
$P C B-138$ & 18 & 13 & 5.9 \\
$P C B-180$ & 16 & 9.3 & 6.4 \\
$\sum$ indicator PCBs g/kg UB & $\mathbf{a}$ & $\mathbf{4 1}$ & $\mathbf{2 4}$ \\
\hline
\end{tabular}

aUB: upper bound

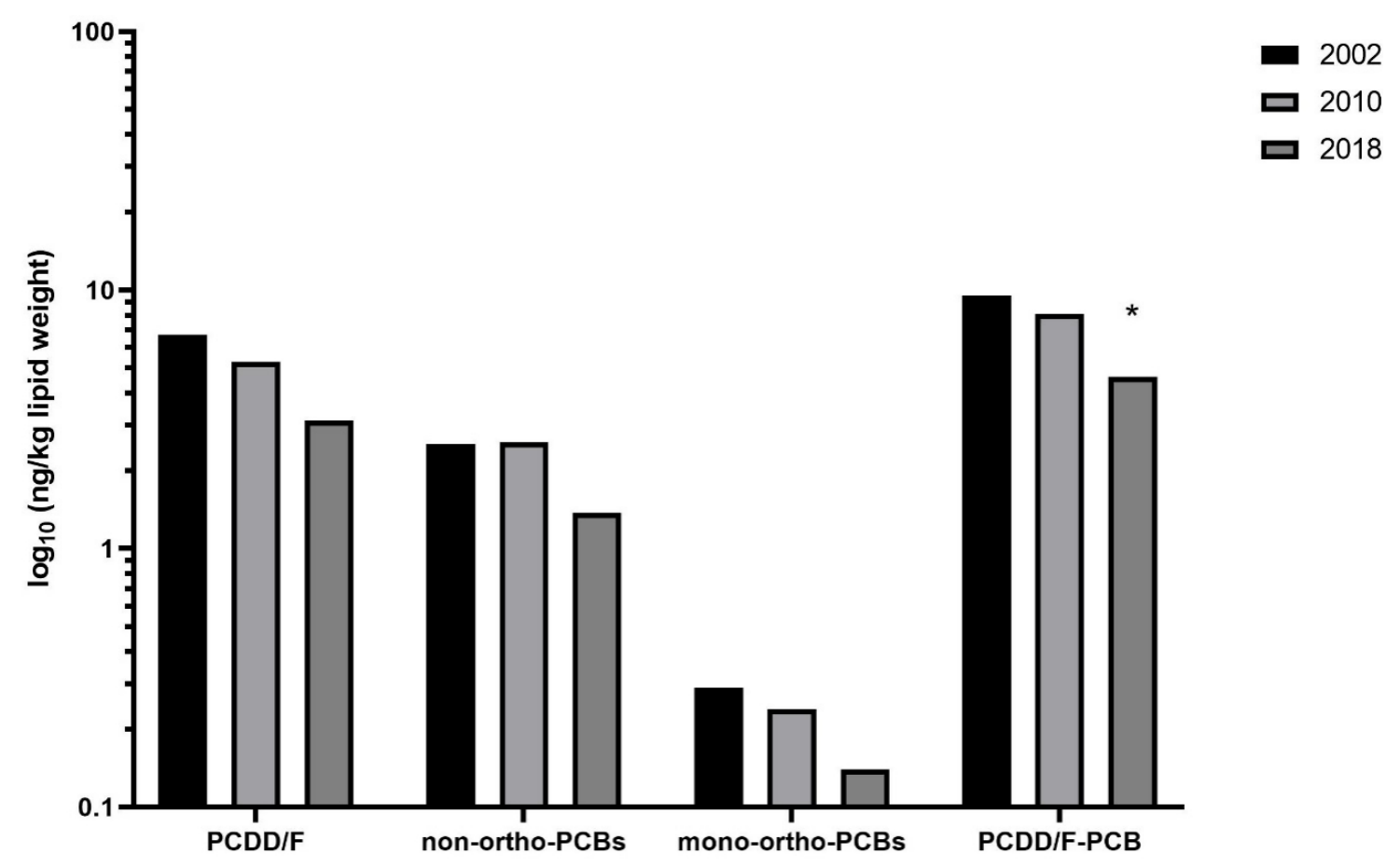

Figure 1. Comparison of mean $\mathrm{WHO}_{2005} / \mathrm{TEQ}$ concentrations for PCDD/Fs, non-ortho-PCBs, mono-ortho-PCBs and $\sum \mathrm{PCDD} / \mathrm{F}+\mathrm{dl}-$ PCB (lipid weight, upper bound) in Irish breast milk from $2002(n=4), 2010(n=11)$ and 2016-18 $(n=16)$ surveys; ${ }^{\star}$ statistical significance between 2010 and 2018, P > 0.005. TEQ: Toxic equivalency; PCDD/F: polychlorinated dibenzo-p-dioxins and furans; PCB: polychlorinated biphenyls; dl: dioxin-like.

Dublin and Galway pools (41\%-42\%) compared to the full data set.

\section{Nursing infants' dietary intake of PCDD/Fs and dl-PCBs}

As described in Estimation of infant intake of PCDD/F and PCBs via breast milk, estimated daily intake values for infants were calculated using $\sum$ PCDD/F TEQ, $\Sigma$ PCB TEQ and $\sum$ PCDD/F + PCB TEQ UB GM concentrations based on a daily intake value of $800 \mathrm{~mL}$ and $1200 \mathrm{~mL}$ breast milk as 14, 6.7, 20, and 21, 10 and $31 \mathrm{pg}$ TEQ $\mathrm{kg}^{-1}$ bw per day, respectively [Supplementary Tables SI-7.1 and SI-7.2]. EFSA does not recommend that exposure data for breastfed infants be compared directly to the TWI of 2 pg TEQ $\mathrm{kg}^{-1} \mathrm{bw}$ per week, as the TWI is based on the mother's intake that would result in concentrations in breast milk leading to a child serum level at age nine (7.0 $\mathrm{pg} \mathrm{WHO}_{2005} \mathrm{TEQ} / \mathrm{g}$ fat) potentially causing adverse effects in 


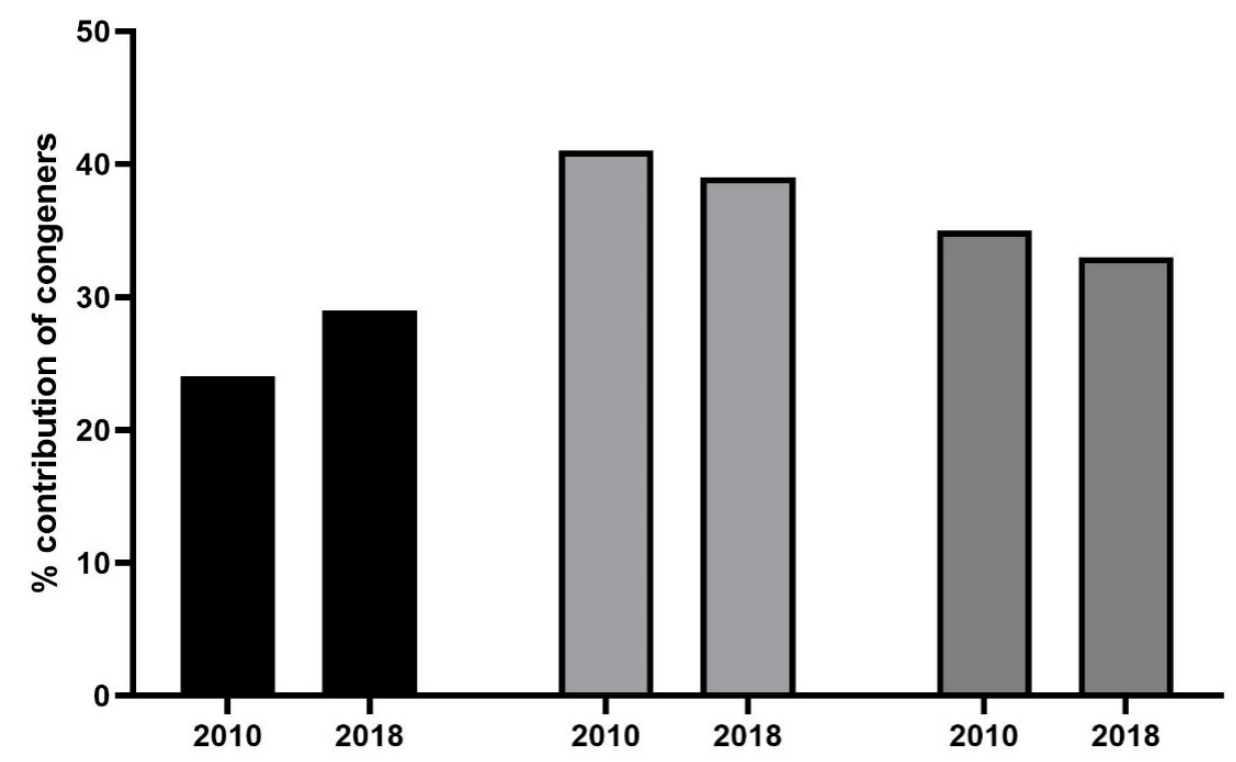

Figure 2. Comparison of percentage contribution of $\mathrm{WHO}_{2005} / \mathrm{TEQ}$ concentrations for PCDF, PCDD and PCBs (lipid weight, Upper Bound $)$ in Irish breast milk from $2010(n=11)$ and 2016-18 $(n=16)$ surveys. TEQ: Toxic equivalency; PCDF: polychlorinated dibenzofurans; PCDD: polychlorinated dibenzo-p-dioxins; PCB: polychlorinated biphenyls.

older children ${ }^{[10]}$. Instead, it is more appropriate to compare concentrations to $5.9 \mathrm{pg}^{\mathrm{TEQ}} \mathrm{g}^{-1}$ fat, the human milk concentration likely to result in the NOAEL serum level of $7.0 \mathrm{pg} \mathrm{WHO}_{2005} \mathrm{TEQ} / \mathrm{g}$ fat at age nine (EFSA, 2018). Reassuringly, our mean WHO PCDD/F + PCB TEQ concentrations are less than 5.9 pg TEQ $\mathrm{g}^{-1}$ fat. However, both the LB and UB concentrations reported for Pools 6 and 9 exceed 5.9 pg TEQ g fat. $^{-1}$ While this exceedance for a small proportion of the population highlights the need for continued efforts to reduce human exposure to dioxin-like chemicals, we note and emphasise the position of WHO, that the positive benefits of breast feeding for both infant and mother significantly outweigh the health risks due to exposure $^{[14]}$.

\section{CONCLUSION}

This study reports concentrations of PCDDs, PCDFs, and PCBs in human milk from first-time mothers in Ireland, sampled from two different maternity hospitals, one in the West of Ireland (Galway) and one in the East of Ireland (Dublin). Concentrations reported are at the low end of those previously reported for Europe and elsewhere.

Significant declining temporal trends are observed when compared to previous Irish milk surveys from 2002 and 2010. There has been a $41 \%$ decrease in mean WHO-PCDD/F TEQ values, a $39 \%$ decrease in mean WHO-PCDD/F-PCB TEQ values, and a $45 \%$ decrease in mean indicator-PCB concentrations. This declining temporal trend concurs with findings elsewhere and likely reflects the beneficial impacts of the measures introduced over the past 16 years under Ireland's National Implementation Plan for POPs under the UNEP Stockholm Convention. WHO-TEF values are due to be re-evaluated in spring 2022, which may result in the lowering of the TEF values for some of the congeners, and in turn, the overall TEQ values.

\section{DECLARATIONS}

Acknowledgement

This project (ELEVATE, reference 2016-HW-MS-8) is funded under the EPA Research Programme 20142020. The EPA Research Programme is a Government of Ireland initiative funded by the Department of 
Communications, Climate Action and Environment. We also acknowledge funding from the Food Safety Authority of Ireland. We gratefully acknowledge all the mothers who donated milk samples, as well as staff in University College Hospital Galway and Coombe Hospital, Dublin, for their help with this study.

\section{Authors' contributions}

Made substantial contribution to study design, participant recruitment, data analysis and interpretation, technical writing: Wemken N, Coggins MA, Harrad S, Tlustos C

Made substantial contributions to sample preparation, sample analysis, data analysis and interpretation, technical writing: Houlihan M

Made substantial contributions to participant recruitment and sample collection: Cellarius C, Cleere K, Morrison JJ, Daly S

Made substantial contributions to sample preparation, sample analysis, data analysis and interpretation:

Keogh M, Tierney J, O’Riordain C, Noone C

\section{Availability of data and materials}

Extra data is published in the Supplementary data.

\section{Financial support and sponsorship}

This project is funded under the EPA Research Programme 2014-2020, Government of Ireland initiative funded by the Department of Communications, Climate Action and Environment and the Food Safety Authority of Ireland.

\section{Conflicts of interest}

All authors declared that there are no conflicts of interest.

\section{Ethical approval and consent to participate}

Study protocols and design were approved by the Clinical Research Ethics Committee of the Galway University Hospital (Ref: C.A. 1578) and the Research Ethics Committee of the Coombe Womens and Infants University Hospital in Dublin (No. 30e2016).

\section{Consent for publication}

Not applicable.

\section{Copyright}

(c) The Author(s) 2021.

\section{REFERENCES}

1. WHO (2016) Dioxins and their effects on human health. Available from: https://www.who.int/news-room/fact-sheets/detail/dioxinsand-their-effects-on-human-health [Last accessed on 12 Nov 2021].

2. Loganathan BG, Masunaga S. PCBs, dioxins, and furans: human exposure and health effects. In: Gupta RC, editor. Handbook of toxicology of chemical warfare agents. Elsevier; 2009. DOI

3. Harrad S, Abdallah MA. The environmental behaviour of persistent organic pollutants. In: Harrison RM, editor. Pollution: causes, effects and control. 5th ed. Royal Society of Chemistry; 2014.

4. Secretariat of the Stockholm Convention United Nations Environmental Programme Stockholm Convention Protection of human health and the environment from persistent organic pollutants (2017). Available from: http://chm.pops.int/Implementation/IndustrialPOPs/PCBs/Overview/tabid/273/Default.aspx [Last accessed on 12 Nov 2021].

5. European Food Safety Authority. Opinion of the Scientific Panel on contaminants in the food chain on a request from the Commission related to the presence of Non-Dioxin like polychlorinated biphenyls (PCB) in feed and food. Available from: https://www.efsa.europa.eu/en/efsajournal/pub/284 [Last accessed on 12 Nov 2021].

6. DeMarch BGE, de Wit C, Muir DCG, Braune BM, Gregor DJ. Persistent Organic Pollutants. Artic pollution issues: a state of the artic environmental report. AMAP Assessment Report; 1997.

7. Khairy MA, Luek JL, Dickhut R, Lohmann R. Levels, sources and chemical fate of persistent organic pollutants in the atmosphere and snow along the western Antarctic Peninsula. Environ Pollut 2016;216:304-13. DOI PubMed 
8. European Commission. Communication from the commission to the council, the European parliament and the Economic and Social Committee Community - strategy for dioxins, furans and polychlorinated biphenyls. Available from: https://www.fsai.ie/uploadedFiles/ECcommunication dioxins.pdf [Last accessed on 12 Nov 2021].

9. Tlustos C, Anderson W, Flynn A, Pratt I. Exposure of the adult population resident in Ireland to dioxins and PCBs from the diet. Food Addit Contam Part A Chem Anal Control Expo Risk Assess 2014;31:1100-13. DOI PubMed

10. Knutsen HK, Alexander J, Barregård L, et al; EFSA Panel on Contaminants in the Food Chain (CONTAM). Risk for animal and human health related to the presence of dioxins and dioxin-like PCBs in feed and food. EFSA J 2018;16:e05333. DOI PubMed PMC

11. EFSA. Peer review of a database of relative effect potencies of PCDDs, PCDFs and PCBs and preparing a review of the use of relative effect potencies for derivation of Toxic Equivalency Factors for dioxin-like compounds. Available from: https://www.efsa.europa.eu/en/call/peer-review-database-relative-effect-potencies-pcdds-pcdfs-and-pcbs-and-preparing-review-use [Last accessed on 12 Nov 2021].

12. van Leeuwen FXR, Malisch R. Results of the third round of the WHO-coordinated exposure study on the levels of PCBs, PCDDs and PCDFs in human milk. Organohalogen Compd 2002;56:311-6. DOI

13. World Health Organization. Fourth WHO-coordinated survey of human milk for persistent organic pollutants in cooperation with UNEP. Guidelines for Developing a National Protocol. Available from: https://www.who.int/foodsafety/chem/POPprotocol.pdf [Last accessed on 12 Nov 2021].

14. van den Berg M, Kypke K, Kotz A, et al. WHO/UNEP global surveys of PCDDs, PCDFs, PCBs and DDTs in human milk and benefitrisk evaluation of breastfeeding. Arch Toxicol 2017;91:83-96. DOI PubMed PMC

15. Pratt IS, Anderson WA, Crowley D, et al. Polychlorinated dibenzo-p-dioxins (PCDDs), polychlorinated dibenzofurans (PCDFs) and polychlorinated biphenyls (PCBs) in breast milk of first-time Irish mothers: impact of the 2008 dioxin incident in Ireland. Chemosphere 2012;88:865-72. DOI PubMed

16. Wemken N, Drage DS, Cellarius C, et al. Emerging and legacy brominated flame retardants in the breast milk of first time Irish mothers suggest positive response to restrictions on use of HBCDD and Penta- and Octa-BDE formulations. Environ Res 2020;180:108805. DOI PubMed

17. Abdallah MA, Wemken N, Drage DS, et al. Concentrations of perfluoroalkyl substances in human milk from Ireland: implications for adult and nursing infant exposure. Chemosphere 2020;246:125724. DOI PubMed

18. Central Statistics Office. Vital statistics yearly summary. 2018. Available from: https://www.cso.ie/en/releasesandpublications/ep/pvsys/vitalstatisticsyearlysummary2018/ [Last accessed on 12 Nov 2021].

19. Commission Regulation (EU) 2017/644 of 5 April 2017 laying down methods of sampling and analysis for the control of levels of dioxins, dioxin-like PCBs and non-dioxin-like PCBs in certain foodstuffs and repealing Regulation (EU) No 589/2014 (Text with EEA relevance). Available from: https://eur-lex.europa.eu/legal-content/EN/TXT/PDF/?uri=CELEX:32017R0644\&from=PL [Last accessed on 12 Nov 2021].

20. Van den Berg M, Birnbaum LS, Denison M, et al. The 2005 World Health Organization reevaluation of human and Mammalian toxic equivalency factors for dioxins and dioxin-like compounds. Toxicol Sci 2006;93:223-41. DOI PubMed PMC

21. Panel on Contaminants in the Food Chain (CONTAM). Scientific Opinion on the presence of dioxins (PCDD/Fs) and dioxin-like PCBs (DL-PCBs) in commercially available foods for infants and young children. EFSA 2012;10:298. DOI

22. Hernández CS, Pardo O, Corpas-Burgos F, et al; BETTERMILK. Biomonitoring of polychlorinated dibenzo-p-dioxins (PCDDs), polychlorinated dibenzofurans (PCDFs) and dioxin-like polychlorinated biphenyls (dl-PCBs) in human milk: Exposure and risk assessment for lactating mothers and breastfed children from Spain. Sci Total Environ 2020;744:140710. DOI PubMed

23. Focant JF, Fréry N, Bidondo ML, et al. Levels of polychlorinated dibenzo-p-dioxins, polychlorinated dibenzofurans and polychlorinated biphenyls in human milk from different regions of France. Sci Total Environ 2013;452-453:155-62. DOI PubMed

24. Giovannini A, Rivezzi G, Carideo P, et al. Dioxins levels in breast milk of women living in Caserta and Naples: assessment of environmental risk factors. Chemosphere 2014;94:76-84. DOI PubMed

25. Schuhmacher M, Mari M, Nadal M, Domingo JL. Concentrations of dioxins and furans in breast milk of women living near a hazardous waste incinerator in Catalonia, Spain. Environ Int 2019;125:334-41. DOI PubMed

26. Roberto M, Fabiola F, Valter C, et al. Chemical indicators of exposure to polychlorodibenzo-p-dioxins, polychlorodibenzofurans and polychlorobiphenyls in breast milk samples from mothers residing in Trento, Italy, and neighboring country municipalities. $J$ Environ Sci Health B 2018;53:510-8. DOI PubMed

27. Chen MW, Castillo BAA, Lin DY, et al. Levels of PCDD/Fs, PBDEs, and PBDD/Fs in breast milk from Southern Taiwan. Bull Environ Contam Toxicol 2018;100:369-75. DOI PubMed

28. Hue NTM, Van Thuong N, Mai PTN, Minh NH. Site-specific bioaccumulation of polychlorinated dibenzo-p-dioxins and polychlorinated dibenzofurans (PCDD/PCDFs) in mothers and their infants living in vicinity of Bien Hoa airbase, Southern Vietnam. Environ Geochem Health 2018;40:2539-49. DOI PubMed

29. Ae R, Nakamura Y, Tada H, et al. An 18-year follow-up survey of dioxin levels in human milk in Japan. J Epidemiol 2018;28:300-6. DOI PubMed PMC

30. Rawn DFK, Sadler AR, Casey VA, et al. Dioxins/furans and PCBs in Canadian human milk: 2008-2011. Sci Total Environ 2017;595:269-78. DOI PubMed

31. Antignac JP, Main KM, Virtanen HE, et al. Country-specific chemical signatures of persistent organic pollutants (POPs) in breast milk of French, Danish and Finnish women. Environ Pollut 2016;218:728-38. DOI PubMed

32. Zhang L, Yin S, Li J, Zhao Y, Wu Y. Increase of polychlorinated dibenzo-p-dioxins and dibenzofurans and dioxin-like polychlorinated biphenyls in human milk from China in 2007-2011. Int J Hyg Environ Health 2016;219:843-9. DOI PubMed 
33. Lu D, Lin Y, Feng C, et al. Levels of polychlorinated dibenzo-p-dioxins/furans (PCDD/Fs) and dioxin-like polychlorinated biphenyls (DL-PCBs) in breast milk in Shanghai, China: a temporal upward trend. Chemosphere 2015;137:14-24. DOI PubMed

34. Croes K, Colles A, Koppen G, et al. Determination of PCDD/Fs, PBDD/Fs and dioxin-like PCBs in human milk from mothers residing in the rural areas in Flanders, using the CALUX bioassay and GC-HRMS. Talanta 2013;113:99-105. DOI PubMed PMC

35. Wong TW, Wong AH, Nelson EA, Qiu H, Ku SY. Levels of PCDDs, PCDFs, and dioxin-like PCBs in human milk among Hong Kong mothers. Sci Total Environ 2013;463-464:1230-8. DOI PubMed

36. Environmental Protection Agency. Ireland's update of national implementation plan for the Stockholm convention on persistent organic pollutants. Available from: https://www.epa.ie/pubs/reports/waste/haz/IE_NIP-Final-Dec_2018\%20_website.pdf [Last accessed on 12 Nov 2021]. 